\title{
Teachers' perception and experience on outcomes-based education implementation in Isabela State University
}

\author{
Krichelle A. Tungpalan, Mila F. Antalan
}

College of Education, Isabela State University-Cauayan Campus, Cauayan City, Isabela, Philippines

\begin{tabular}{l} 
Article Info \\
\hline Article history: \\
Received Jan 15, 2021 \\
Revised Aug 8, 2021 \\
Accepted Sep 8, 2021 \\
\hline
\end{tabular}

\section{Keywords:}

Experience Faculty member

Outcomes-based education

Perception

Teachers

\begin{abstract}
The existing typology established by the Commission on Higher Education (CHED) and the introduction of outcomes-based education (OBE) has created numerous demands and challenges for higher education in the Philippines. Hence, this study analyzed the scope of expertise and experience of Isabela State University-College of Computing Studies, Information and Communication Technology faculty members in the 2nd semester of study year 2018-2019 to identify OBE implementation. In this study, a mixedmethod approach was used for data and information collection. Weighted mean was used to interpret the extent of knowledge and actual practice of the faculty members and on the qualitative part, data were analyzed using thematic analysis. The results of this study indicate a great deal of expertise and experience on the implementation of OBE among the faculty members of the College of Computing and Information Communication Technology at Isabela State University Cauayan Campus. The faculty members are well versed in the application and practice of OBE and will continue to contribute to the realization of the goals of OBE by practice.
\end{abstract}

This is an open access article under the CC BY-SA license.

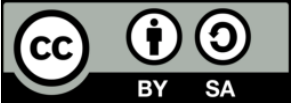

\section{Corresponding Author:}

Krichelle A. Tungpalan

College of Education

Isabela State University-Cauayan Campus

Cauayan City, 3305, Isabela, Philippines

Email: tungpalankrichelle@gmail.com

\section{INTRODUCTION}

In today's world, everything changes drastically and continuously. With these changes, additional skills are mandatory to work with the developing technology. In order to remain responsive to these challenges, tertiary education should provide both professional knowledge/skills and all-round attributes to the graduates [1]. Academic institutions of higher learning strive not only to prepare students for life and work, but also to provide them with substantial educational programs that are profoundly embedded in their duty to develop the nation's character [2].

In order to meet international expectations, educators around the world are exploring new approaches to improve education, including curriculum review, training systems, and assessment methods. This leads to a change from conventional content-based education to output-based education [3]. The outcomes-based education (OBE) falls within the context of competency-based learning standards and performance-based quality assurance monitoring. This is widely acknowledged as the most important aspect of education in a knowledge-based economy society [4]. Students have been found to have a higher propensity to be more active after education in some Philippine universities since the adoption of OBE [5], and in terms of developing academics, teaching and attitude, OBE was helpful [6] with OBE-knowledgeable faculty who make a major contribution to the achievement of institutional and program objectives [7]. 
OBE offers another way of measuring the success of university students from a related viewpoint [8]. Another model used in the evaluation of student performance is rubrics. It is used when evaluating the consistency of learners' performance appraisal work [9]. Rubrics help explain ambiguous, unclear goals, help students understand their objectives, help students develop themselves, encourage improved student results, make scoring easier and quicker, make scoring more precise, impartial, and reliable, enhance student input, minimize student arguments, improve faculty and staff feedback [10].

Spady's [11] OBE model is based on three assumptions and four principles. These expectations are that all students can learn and succeed, but not on the same day or in the same way; that successful learning promotes even more effective learning; and that schools control the factors that directly affect successful learning. While OBE has been promoted for more than 60 years and Spady [11] resurrected it in the 1980s, educators, parents, and students received strong negative feedback. One such reaction was to teach predetermined learning outcomes that are "overly precise, observable, quantifiable and so limited that they can be restricting rather than freeing, which can contribute to the rigidification of teaching, reductionism, reification, fractionation, serendipity, and may fail to accomplish the type of learning and education it intends to encourage" [12], [13].

There were a number of critiques of the OBE curriculum at the beginning of its introduction. However, there are several educational institutions that have implemented a new program, believing that it is for the benefit of the student. Education should be structured to prepare graduates for the workplace and to demonstrate their core competencies [14]. Most higher education institutions in Philippines are currently focusing on implementing OBE in order to meet the demands of international universities and colleges [15]. Updated curricula to comply with OBE will assist graduates in gaining the requisite skills in a fast-changing and global labor market [16] while one of the accreditation criteria for assessing the development of trained professionals is to conduct research [17].

Studies that showed students' self-rating of competence and trust have increased over time are compensating for these criticisms [18]. Studies also found that the outcome-based curriculum has enabled the learning of awareness, skills, and attitudes relevant to subjects [19]. Students have been found to have a higher propensity to be more active after education in some Philippines universities since the adoption of OBE [5] and in terms of developing academics, teaching, and attitude, OBE was helpful [6]. With OBEknowledgeable faculty who make a major contribution to the achievement of institutional and program objectives [15]. In addition, the faculty are able to match curriculum and pedagogy such as module design and implementation as well as evaluation tasks and activities with the expected results when learning outcomes are specified in explicit and precise terms [20].

The effectiveness of the implementation of the OBE depends strongly on educators, so full understanding and awareness of the OBE is needed. It would take a great deal of willingness and tremendous effort to adopt new ideas and new skills to change the model from the traditional to an OBE approach. Bold and realistic structural projects must be implemented and embraced in order to swing the existing mindset in a new way [21].

The highlights of the outcomes-based approach guide educators to choose effective teaching methods, to establish and use a broad variety of evaluation measures, and to determine whether or not the learner has attained the outcome. Javier [15] claimed that it has to provide the goods and services needed to achieve the results it wants to generate as an educational institution. The degree to which an organization understands the OBE's meaning and importance has a direct impact on its application. The fundamental task of the teacher is to get students to engage in learning activities that are likely to lead them to achieve the desired results in a relatively successful manner if they are to learn the desired results in a relatively successful manner [22].

Like many other universities in the country and in Asia, the Isabela State University Cauayan campus particularly in the College of Computing Studies and Information Communication Technology adopted OBE principles and standards in the teaching and learning process. However, the extent of implementation of faculty members and their readiness in terms of knowledge and application in their respective classes are not being supervised and evaluated. Therefore, this study was conducted to determine the extent of knowledge and practice of Isabela State University faculty members with regards to OBE. With this, the researcher believes that doing so would give the administrators and teachers a clear picture of how well OBE is being applied in instruction and assessment. This would enable them to address and remedy difficulties as well as improve OBE implementation in the institution.

\section{RESEARCH METHOD}

The mixed method approach design was utilized in gathering the necessary data and information regarding the knowledge and practices as well as the experiences of the College of Computing Studies, 
Information and Communication Technology (CCSICT) faculty members on the outcomes-based education (OBE) implementation. The mixed method approach was adopted as a process to gather and integrate data collected in both quantitative and qualitative processes.

Quantitative analysis was employed to determine the extent of knowledge and practices on OBE implementation and the significant relationship between the faculty members' extent of knowledge and practices on the OBE implementation. In order to validate the findings in the quantitative data, qualitative analysis was also utilized to determine the CCSICT faculty members' experiences and observations in the implementation of OBE in the teaching and learning process.

\subsection{Participants}

This study was conducted in the CCSICT of Isabela State University, Cauayan City Campus during the second semester of the school year 2018-2019. The respondents in the quantitative data was obtained by complete enumeration, where all the respondents of the whole population were assessed. The survey was carried out with 13 CCSICT faculty members for the quantitative data. The respondents on the qualitative data were composed of five CCSICT faculty members and were selected through purposive sampling. The interview sessions were conducted during the second semester of the school year 2018-2019.

\subsection{Data collection}

The quantitative data was collected through a research-made questionnaire to assess the CCSICT Faculty extent of knowledge and practices towards OBE standards. The questionnaire deals with the knowledge and practice of the OBE standard. Content validation was conducted wherein experts asked to evaluate the indicators in the survey questionnaire and was piloted to selected faculty members from other campuses to confirm the interpretation of the questions and the validity of the survey. Qualitative data was collected using an interview to describe the experience and observations of the CCSICT Faculty in an outcomes-based teaching and learning framework. Five questions were asked to the five faculty members of CCSICT as guided by a semi-structured interview.

\subsection{Data analysis}

Weighted mean was used to interpret the extent of knowledge and actual practice of the 20 faculty members of the CCSICT of Isabela State University on the implementation of OBE. On the qualitative part of the study, data were analyzed using thematic analysis. The transcripts of the interview were organized, synthesized, and examined for the common statements and ways of thinking. The data then was arranged according to themes. Table 1 presents and interprets the gathered data from the questionnaire.

Table 1. Arbitrary guide

\begin{tabular}{ccc}
\hline Weight & Range & Verbal interpretation \\
\hline 5 & $4.50-5.00$ & Very great extent (VGE) \\
4 & $3.50-4.49$ & Great extent (GE) \\
3 & $2.50-3.49$ & Moderate extent (ME) \\
2 & $1.50-2.49$ & Less extent (LE) \\
1 & $1.00-1.49$ & No extent (NE) R \\
\hline
\end{tabular}

\section{RESULTS AND DISCUSSION}

\subsection{Faculty members' perception in OBE implementation and standards}

Table 2 reflects the knowledge of OBE implementation and standards of the faculty member of College of Computing Studies and Information Technology. As shown in Table 2, CCSICT faculty members have a great extent of knowledge and awareness of how to provide guidance in a student-centered manner, and their comprehension of OBE training is successful in the delivery of instruction, with a mean of 4.46.

Understanding the principle of designing rubrics for outcome-based assessment obtained the weighted mean score 4.38. It is obvious that OBE implementation is more apparent in terms of procedures in having well-defined evaluation standards that are clear to both teachers and learners about how assessment will take place. This supports Caguimbal, et al. [23] findings that a well-defined evaluation criterion, which makes it transparent to both assessors and learners how assessment will take place, is an important benefit of OBE. The most significant disadvantages of OBE are the requirements for all learning materials to be rewritten, which necessitates a significant expenditure of time and money.

Meanwhile, having clear understanding how institutional or graduate attributes are formulated obtained the least weighted mean 3.77 with great extent verbal interpretation. It can be noted, however, that the result of the study is validated by the study of Borsoto, et al. [6] that OBE helps students develop the necessary knowledge and skills they need to excel in the practice of their future careers. 
Table 2. Knowledge and awareness of OBE implementation and standards

\begin{tabular}{lcc}
\hline \multicolumn{1}{c}{ Items } & $\begin{array}{c}\text { Verbal } \\
\text { interpretation }\end{array}$ & Mean \\
\hline 1. I understand the alignment of Intended learning outcomes to the university's mission and vision. & 4.00 & Great extent \\
2. I can figure out how institutional or graduate attributes are formulated. & 3.77 & Great extent \\
3. I have a clear understanding on Outcomes-based Teaching and Learning (OBTL) framework. & 4.08 & Great extent \\
4. I am familiar with the alignment of intended learning outcomes to Teaching \& Learning Activities & 4.23 & Great extent \\
(TLAs) and Assessment Tasks (ATs). & 3.8 \\
5. I understand how the OBTL approach is being facilitated in the class. & 4.46 & Great extent \\
6. I know how to use a student-centered approach to provide guidance. & 4.15 \\
7. I have knowledge on constructing course intended outcomes using Bloom's taxonomy. & 4.15 \\
8. I am aware of the difference between traditional method of teaching and OBTL framework. & 4.23 & Great extent \\
9. I have knowledge on the assessment techniques for OBE and OBTL. & 4.38 & Great extent \\
10. I understand the principle of designing rubrics for outcome-based assessment. & 4.08 & Great extent \\
11. I am aware of the different teaching methods that will best facilitate in achieving the learning & \\
outcomes. & 4.31 \\
12. I am familiar with the alignment of learning outcomes with assessment task. Great extent \\
13. I know and understand that trainings on OBE are effective in the delivery of instruction. & 4.46 & Great extent \\
14. I know where to start with an Outcomes-based Teaching and Learning approach in the classroom. & 4.20 & Great extent \\
15. I am aware that Outcomes-based Teaching and Learning necessitates teachers to devise teaching & 4.35 \\
and learning activities. & Great extent \\
\end{tabular}

There is also a great extent of knowledge among participants about the alignment of expected learning outcomes to Teaching \& Learning Activities (TLAs) and Assessment Tasks (ATs), with a weighted mean score of 4.23 with great extent for its verbal interpretation. The finding of the study associates with the result conducted by Liu, Bridgeman, and Adler [24] that the focus of active OBE implementation is the clear definition of learning outcomes and the development of methods to ensure students' achievement.

The calculated grand mean score of 4.18 indicates that the faculty members of the CCSICT have a high level of expertise in OBE implementation and standards. This is the result of management's efforts to hold a series of workshops for faculty and staff on how the OBE will be applied at various levels and areas of instruction and school management. As Evardo [25] pointed out, the administrators' and management team's efforts in delivering a series of OBE workshops for faculty members greatly aid in learning the basic areas of OBE in teaching.

Table 3 reveals the OBE practices and standards of the faculty member of CCSICT. As shown in Table 3, there is a very great extent on the practice of the faculty members in terms of knowing how to utilize teaching methods and strategies that are most applicable for implementing, conducting teaching and learning activities that are highly student-centered and attending series of OBE trainings and seminars to improve their instruction were a common OBE practice among the CCSICT faculty members with the highest mean of 4.77. Since the integration of instruction and testing is heavily stressed in OBE, Mulenga and Kabombwe [26] argued that the consistent use of various ways of measurement should be taken into account in order to accommodate variations in student learning styles. In OBE, a number of teaching methods and approaches have to be used to promote further student participation. Furthermore, Nicholson [27] stressed the importance of teachers preparing and implementing an active teaching environment by allowing students to participate in the process.

Participants also have a great deal of awareness of offering opportunities for collective learning and measuring student success on the basis of the results that they are expected to show with a weighted mean of 4.23. According to Guzman, Edaño, and Umayan [1], the participants' top priorities for faculty leadership training were constructive and integrated learning management, teacher-student teaching readiness, and higher-level thought skills. Furthermore, there is also a great extent on the practice of the participants in terms of using rubrics to assess the degree of learning that has taken place in a given course, working on innovative and interactive teaching and learning activities that will stimulate the minds of the students and help them create and integrate knowledge about the course content and intended learning outcomes, and also employing a variety of teaching and learning exercises that allow my students submit, invent, produce new ideas, diagnose and solve problems with a weighted average of 4.00. This study also confirmed the use of a combination of classroom teaching and learning experiences for more student-centered practices by the Maritime Faculty Member at Lyceum International Maritime Academy (LIMA) [22].

However, involving the CCSICT faculty in the formulation of program outcome of the college/institute formulated obtained the least weighted mean 3.54 with great extent verbal interpretation. This implies that there is a need to consult the different stakeholders such as the parents, students, an especially teachers in the formulation of the program outcomes. The calculated grand mean score of 4.21 shows that OBE procedures and expectations are well-understood. In a study by Laguador and Dotong [28], 
faculty members with a high level of experience and knowledge of OBE implementation would have a greater capacity to contribute to the achievement of OBE targets by practice.

Table 3. OBE practices and standards

\begin{tabular}{|c|c|c|}
\hline Items & Mean & Verbal interpretation \\
\hline 1. I was active in the creation of the College/program Institute's results. & 3.54 & Great extent \\
\hline $\begin{array}{l}\text { 2. I created syllabi that demonstrate how institutional/graduate attributes are linked to the } \\
\text { desired learning outcomes and course outcomes. }\end{array}$ & 4.31 & Great extent \\
\hline 3. I conducted teaching and learning activities that are highly student-centered. & 4.77 & Very great extent \\
\hline $\begin{array}{l}\text { 4. I utilize teaching methods and strategies that are most applicable for implementing the } \\
\text { learning outcomes and aligned with the assessment task. }\end{array}$ & 4.77 & Very great extent \\
\hline 5.I utilized authentic assessment activities to determine student learning. & 3.92 & Great extent \\
\hline 6. I provided opportunities for collaborative learning. & 4.23 & Great extent \\
\hline 7. I used appropriate verbs in my syllabi to express the desired learning outcomes. & 4.38 & Great extent \\
\hline 8. I created teaching and learning opportunities to help students achieve their goals. & 4.31 & Great extent \\
\hline 9. I provided feedback on my student performance. & 4.31 & Great extent \\
\hline 10. I employed rubrics to assess the degree of learning that has taken place in a given course. & 4.00 & Great extent \\
\hline $\begin{array}{l}\text { 11. I used creative and immersive teaching and learning exercises to stimulate students' minds } \\
\text { and assist them in creating and integrating information about the course material and learning } \\
\text { objectives. }\end{array}$ & 4.00 & Great extent \\
\hline $\begin{array}{l}\text { 12. I evaluated my students' performance based on the outcomes that they are required to } \\
\text { demonstrate. }\end{array}$ & 4.23 & Great extent \\
\hline 13. I attended series of OBE trainings and seminars to improve my instruction. & 4.77 & Great extent \\
\hline $\begin{array}{l}\text { 14. I used positive alignment, which begins by explicitly specifying the learning outcomes, } \\
\text { which are statements about what the learner should be able to do and at what level. }\end{array}$ & 3.85 & Great extent \\
\hline $\begin{array}{l}\text { 15. I used a variety of teaching and learning activities to encourage my students to submit, } \\
\text { innovate, create new ideas, diagnose problems, and solve them. }\end{array}$ & 4.00 & Great extent \\
\hline Grand mean & 4.21 & Great extent \\
\hline
\end{tabular}

\subsection{Faculty members' experiences and observations in OBE implementation and standards}

To support the data collected from the survey questionnaire, a semi-structured interview was conducted in which select faculty members from the College of Computing Studies and Information Communication Technology of Isabela State University Cauayan Campus were asked questions about their experiences and observations of the OBE implementation and standards in the institution.

When asked about their awareness regarding OBE and its concepts, it was revealed that a majority of them first encountered these during the year that the Commission on Higher Education required HEIs to transform their curriculum and align this according to the principles of OBE. For instance, one of the participants announced:

Initially, I have heard it over a meeting that the university required instructors to develop what was called OBEdized syllabi for the courses being taught. I remembered that there were also some in-house seminars to help the instructors understand OBE and how to implement it in syllabus-writing, instruction planning, and assessment.

The perspective of other participants is very similar to that of the previous participant:

I remember that there were directives from CHED which called for HEIs' compliance. From then on, I attended different seminars and training on $O B E$.

In Article III, Sections 11 to 13, the said memorandum indicated CHED's rationale for adopting an outcomes-based QA monitoring and evaluation: the shift in educational discourse from transmission of expert knowledge to building learner competencies for lifelong learning; this being the key to adapting to the evolving requirements of the 21st century; and CHED's belief in OBE's effectiveness in impeding the spread of infectious diseases [29].

Additionally, all of the participants also talked about the difference between OBE from the traditional teaching approach. For example, Participants 1 and 3 indicated respectively:

Well, for me, outcomes-based learning is very different from the traditional form of teaching and learning. It's an educational theory where it focuses on the attainment of goals. It means that by the end of every educational experience or course, the students have learned and achieved the goals set from the start of the course. OBE does not only focus on theory but on the capability of the students to do the intended learning outcomes and be able to 
demonstrate, judge, and apply the learning and skills gained. Traditional education used a teacher-centered approach while OBE uses a student-centered approach. And I have a positive outlook on $O B E$ than the traditional approach. For me, the traditional teaching approach is you do the talk and demonstrate while OBL lets the learner do it at its own pace, meaning until it satisfies the objective. That's why I preferred OBE because students' performance is assessed more.

This positive response of teachers on the implementation of OBE proved that they have a positive impression regarding OBE. Similarly, in a study conducted by Lui and Shum [30] that if teachers' attitudes towards OBE are unfavorable or resistant, its application might encounter serious issues. Furthermore, Custodio, Espita, and Siy [31] noted that while a transition from a teacher/expert to a student-centered approach has been linked to better results, teachers and students are also expected to change their attitudes and behaviors toward schooling.

The participants were also asked about the OBE teaching and learning strategies they utilized for the effective delivery of instruction. OBE encouraged teaching that is student-centered and student-controlled where content, events, materials and paces can be influenced by students. Participant 4 said:

It depends. But mostly, I used different strategies aside from the usual lecture and discussions like brainstorming, role-playing, think-team-share, gamification, and others. Because using various strategies will help my students develop their own skills and discover new ones.

Participant 3 talked about the emphasis on the power to transform the learning experience of students for enhancing their knowledge and skills.

Instead, it enables them to learn knowledge and establish a better thinking process that would allow them to earn bread and butter and be successful in the long term. Giving them hands-on applications (mostly computer works) in-order for them to work independently to make learning better than memorizing the concepts and theory of the course.

The cornerstone of OBE is an active, dynamically educated classroom in which learners are interested in generating outputs and products and helping to enhance the quality of learning. According to Caguitla, et al. [22], if students are learning the desired outcomes in a relatively successful manner, then the main role of the instructor is to get students to engage in learning activities that are likely to result in the achievement of those outcomes. In addition, the participants were also asked about how they monitor, assess, and report student progress and performance. Participant 1 said:

I make use of rubrics for monitoring and assessment. Rubrics make the entire process more objective.

Similarly, participant 3 also talked about rubrics and how these help in the objectiveness of the performance assessment:

Rubrics are helpful. This confirms that I am grading my student in an objective way. I give updates on the progress of my student's performance.

Participant 5 also cited rubrics which is an effective assessment tool for measuring progress and performance. He said:

For me, rubrics are very helpful to the students. They will be informed of the criteria for what they are expected to do in these practice exams. And also, they perform better when they know what is expected of them.

While, participants 2 and 4 about rubrics, written examinations, and logbooks.

I use rubrics as a basis for assessing my student's output/ outcomes. I also use logbooks and student's evaluations of their classmate's output or other pieces of evidence showing their performance. I think aside from using rubrics, I still used written examinations to monitor, assess, and report student progress and performance. I see to it at least that the written tests I 
give items in higher-order thinking skills that allow students to think critically and to use the knowledge they have learned.

Another model used in the estimation of student performance is rubrics. It is used when evaluating the consistency of the learners' performance evaluation work [32]. Using a heading for self-assessment and tracking, students will check their progress and determine the outcome of their work. Enhancing the strategic use of evaluation criteria, teachers should establish practices that enable students to focus on the learning process [33].

\section{CONCLUSION}

The findings of this study showed that the faculty members of the College of Computing and Information Communication Technology at Isabela State University Cauayan Campus have a great extent of expertise and experience with outcomes-based education (OBE) implementation. The faculty members are well-versed in the application and implementation of outcome-based teaching, and they will continue to contribute to the practical achievement of OBE objectives. The faculty members of the College of Computing and Information Communication Technology at Isabela State University Cauayan Campus have a working knowledge of the standards and practices set out in the findings of the survey. This was further corroborated during the interview when they were asked to expound on how they perceived and apply OBE in instruction, monitoring and assessment.

School administrators should fully promote the professional development of faculties, such as continuing involvement in trainings and workshops on OBE changes and the preparation of curricula mapping and syllabus. In addition, other colleges at Isabela State University Cauayan Campus may conduct relevant research which may provide strong empirical data on the implementation, utilization and effectiveness of OBE, as well as the problems encountered.

\section{ACKNOWLEDGEMENTS}

The conduct of this research would have not been possible without the support of the Isabela State University and its officials headed by University President, Dr. Ricmar P. Aquino, Executive Officer of Cauayan campus, Dr. Precila C. Delima. We also acknowledge the support and assistance of the university and campus officials for research throughout the process.

\section{REFERENCES}

[1] M. F. D. De Guzman, D. C. Edaño, and Z. D. Umayan, "Understanding the Essence of the Outcomes-Based Education (OBE) and Knowledge of its Implementation in a Technological University in the Philippines," Asia Pacific Journal of Multidisciplinary Research, vol. 5, no. 4, pp. 64-71, 2017.

[2] A. O. Macatangay, et al., "Status of Implementation and Usefulness of Outcomes-Based Education in Customs Administration Program of one Asian University," Asia Pacific Journal of Education, Arts and Sciences, vol. 3, no. 3, pp. $62-69,2016$.

[3] P. B. Reyes, "Implementation of a Proposed Model of a Constructivist Teaching-Learning Process-A Step Towards an Outcome Based Education in Chemistry Laboratory Instruction," Asia Pacific Journal of Multidisciplinary Research, vol. 1, no. 1, pp. 174-187, 2013.

[4] R. Nakkeeran, R. Babu, R. Manimaran, and P. Gnanasivam, "Importance of Outcome based education (OBE) to advance educational quality and enhance global mobility," International Journal of Pure and Applied Mathematics, vol. 119, no. 17, pp. 1483-1492, 2018.

[5] I. L. An, "Impact of outcome-based education instruction to accountancy students in an Asian University," Asia Pacific Journal of Education, Arts and Sciences, vol. 1, no. 5, pp. 48-52, 2014.

[6] L. D. Borsoto, J. D. Lescano, N. I. Maquimot, M. J. N. Santorce, A. F. Simbulan, and A. M. Pagcaliwagan, "Status of implementation and usefulness of outcomes-based education in the engineering department of an Asian university," International Journal of Multidisciplinary Academic Research, vol. 2, no. 4, pp. 14-25, 2014.

[7] C. Mercado and H. Lagto, "Understanding the readiness of implementing outcome-based education among selected higher education institutions in Philippines," AU-eJournal of Interdisciplinary Research, vol. 3, no. 1, 2018.

[8] N. C. Camello, "Factors affecting the engineering students' performance in the OBE assessment examination in mathematics," International Journal of Academic Research in Progressive Education and Development, vol. 3, no. 2, pp. 87-103, 2014.

[9] Y. Gabuyo, Assessment of Learning I. Rex Printing Company Inc., Sta. Mesa Heights Quezon City, 2012.

[10] B. E. Walvoord and V. J. Anderson, Effective grading: A tool for learning and assessment in college. John Wiley \& Sons, 2011

[11] W. G. Spady, Outcome-Based Education: Critical Issues and Answers. American Association of School Administrators, Arlington, 1994. 
[12] P. Hill, "Online educational delivery models: A descriptive view," Educause Review, vol. 47, no. 6, pp. 84-86, 2012.

[13] M. Tam, "Outcomes-based approach to quality assessment and curriculum improvement in higher education," Quality Assurance in Education, vol. 22, no. 2, pp. 158-168, 2014.

[14] A. P. Valdez, "Competencies of Career-Entry Medical Technology Graduates of Lyceum of Batangas: Basis for Enhancement of the Internship Training Program," JPAIR Multidisciplinary Journal, vol. 4, no. 1, pp. 16-33, 2010.

[15] F. V. Javier, "Assessing an Asian University's Organizational Effectiveness Using the Malcolm Baldridge Model," Asian Journal of Business and Governance, vol, 2, no. 1, p. 231, 2013.

[16] B. E. Bay Jr, "Integration of technology-driven teaching strategies for enhancing Photojournalism Course," Educational Research International, vol. 2, no. 2, pp. 155-164, 2013.

[17] M. Gómez and C. Panaligan, "Level of research competencies and satisfaction of the faculty members from the college of criminology," Asian Academic Research Journal of Social Science and Humanities, vol. 1, no. 14, pp. 39-55, 2013.

[18] A. M. Morcke, T. Dornan, and B. Eika, "Outcome (competency) based education: an exploration of its origins, theoretical basis, and empirical evidence," Adv Health Sci Educ Theory Pract., vol. 18, no. 4, pp. 851-863, 2013.

[19] H. M. Er, et al., "Twelve tips for institutional approach to outcome-based education in health professions programmes," Medical Teacher, vol. 43, pp. S12-S17, 2019, doi: 10.1080/0142159X.2019.1659942.

[20] K. Dobbins, S. Brooks, J. J. Scott, M. Rawlinson, and R. I. Norman, "Understanding and enacting learning outcomes: the academic's perspective," Studies in Higher Education, vol. 41, no. 7, pp. 1217-1235, 2016.

[21] S. Hoidn, Student-centered learning environments in higher education classrooms. Palgrave Macmillan, 2016.

[22] M. Caguitla, et al., "The Perception of Marine Students towards the Just English Please Program," Unpublished Student Research, Lyceum International Maritime Academy, 2013

[23] D. A. Caguimbal, D. C. Delacion, A. O. Medina, M. S. Mendoza, R. J. M. Mendoza, and M. M. Sanchez, "Level of awareness of the maritime students on the outcomes-based education," Educational Research International, vol. 2 , no. 1, pp. 7-12, 2013.

[24] O. L. Liu, B. Bridgeman, and R. M. Adler, "Measuring learning outcomes in higher education: Motivation matters," Educational Researcher, vol. 41, no. 9, pp. 352-362, 2012.

[25] M. A. Evardo, "Perspectives and preparedness on the Outcomes-based Education (OBE) implication in the higher education institutions of BOHOL," Journal of World Englishes and Educational Practices, vol. 2, no. 2, pp. 46-52, 2020.

[26] I. M. Mulenga and Y. M. Kabombwe, "Understanding a competency-based curriculum and education: The Zambian perspective," Journal of Lexicography and Terminology, vol. 3, no. 1, pp. 106-134, 2019.

[27] A. C. Nicholson, "Comparison of selected outcomes based on teaching strategies that promote active learning in nursing education," PhD Dissertation, University of Iowa, 2010.

[28] J. M. Laguador and C. I. Dotong, "Knowledge versus practice on the outcomes-based education implementation of the engineering faculty members in LPU," International Journal of Academic Research in Progressive Education and Development, vol. 3, no. 1, pp. 63-74, 2014.

[29] Commission on Higher Education (CHED), Handbook on Typology, Outcomes-Based Education, and Institutional Sustainability Assessment. Commission on Higher Education Office of Institutional Quality Assurance and Governance HEDC Building, CP Garcia Avenue, 2014.

[30] G. Lui and C. Shum, "Outcome-Based Education and Student Learning in Managerial Accounting in Hong Kong," Journal of Case Studies in Accreditation and Assessment, vol. 2, no. 1, pp. 1-13, 2012.

[31] P. C. Custodio, G. N. Espita, and L. C. Siy, "The Implementation of Outcome-Based Education: The Case of the University of Perpetual Help System DALTA Las Piñas Campus," Asia Pacific Journal of Multidisciplinary Research, Vol. 7, No. 4, 2019.

[32] M. Guzman, "Preferred student-centered strategies in teacher education: Input to outcomes-based instruction," Asia Pacific Journal of Education, Arts and Sciences, vol. 3, no. 1, pp. 40-48, 2016.

[33] J. Fraile, E. Panadero, and R. Pardo, "Co-creating rubrics: The effects on self-regulated learning, self-efficacy and performance of establishing assessment criteria with students," Studies in Educational Evaluation, vol. 53, no. 1, pp. 69-76, 2017. 